\title{
Investigation of soil-steel interface behavior of Iraqi soil by direct shear apparatus
}

\author{
Omar Al-Emami * \\ *School of Energy, Geoscience, Infrastructure and Society, Heriot-Watt University, United Kingdom
}

\begin{abstract}
Soil - structure interaction is an important theme observed in many civil engineering structures like fondations. The interface shear strength plays a significant role in the analysis and design of many structures constructed above or under the ground. In this study, a total of 28 specimens were tested at vertical stresses of 100,200 , and $400 \mathrm{kPa}$ using direct shear apparatus under consolidated drained condition. A silty sand soil, as per USCS classification system was prepared in the laboratory at different water contents $(4.5 \%, 8.8 \%$, and $12.5 \%)$ and voids ratios $(0.4,0.6,0.8$, and 1$)$. The frictional resistance of this soil was measured. The soil samples were also sheared against three steel surfaces of different textures (smooth, moderate-rough, and rough). The experimental results showed that the steel surface texture is an effective factor in soil-steel interface shear strength. The interface shear strength of the rough steel surface was found higher than smooth and semi-rough steel surfaces. In addition to the surface roughness, the water content and void ratio also play important roles in interface shear strength.
\end{abstract}

\section{Introduction}

The interface is usually defined as a contact zone between two bodies. The serviceability of the geotechnical structures is highly dependent on the behaviour of the layer of soil forming close to the structure surface (i.e. interface layer). Numerous previous studies reported the crucial role of the interface behaviour in analysis of the some geotechnical problems like a retaining wall and the skin friction along a pile shaft. Briaud et al. [6] indicated that $43 \%$ of the resistance along a rigid concrete pile shaft embedded in stiff clay is provided by skin friction. Whereas, Smith and Ray [7] reported that the frictional resistance generated along a concrete pile shaft contributed about $84 \%$ of the total soil resistance subjected to a lateral loading. Extensive researches have been performed to investigate the interface shear strength behaviour between soil and different types of materilas under different test conditions (dry and saturated) [2, 9, 1, 4, 3, $5,10,11]$ using a variety of equipment, e.g., direct shear $[2,8]$, annular shear device [9], Ring torsion apparatus [4], and simple shear [3]. Their outcomes revealed that the interface shear strength depends on different factors like structure interface condition (i.e. rough, intermediate and smooth), type of construction materials (i.e. concrete, steel, wood and geotextile), moisture content, grain size distribution, different types of soil (i.e. clay, sand and silt), void ratio and normal stress. Potyondy [2] has performed earlier soil structure interface research.
This manuscript was submitted on May 15, 2017. This work is supported by Iraqi Ministry of Higher Education and Scientific Research under grant of scholarship.

O. H. AL-Emami is a PhD student at School of Energy, Geoscience, Infrastructure and Society, Heriot-Watt University, Edinburgh, United Kingdom (e-mail: oha31@hw.ac.uk). Former faculty member, Building and Construction Engineering Department, University of Technology, Iraq

He performed numerous laboratory interface direct shear tests to find out the value of frictional resistance between soil and several types of materials (steel, concrete, and wood). The experimental results showed that the angle of internal friction and cohesion should be considered in calculating of skin friction of cohesive soils. He also indicated that the most important factors influencing on the interface shear strength are surface roughness, applied vertical stress, water content, soil composition, and solid material roughness. Kulhawy and Peterson [12] conducted a series of direct shear tests between sand and various surface roughness of concrete to evaluate the influence of surface roughness on the interface shear strength. They pointed out that the surface roughness has a significant impact on the interface shear strength and that the interface friction angle increased with increasing of surface roughness. Their results showed that the angle of friction of soil is greater than the interface friction angle of both smooth and rough surfaces. In another work, Desai et al., [8] studied the properties of sand against concrete interface with different densities, postulating that the interface behaviour greatly influenced by relative density of sand, magnitude of vertical stress, and rate of shear displacement.

\footnotetext{
* Corresponding author: oha31@hw.ac.uk
} 
Tsubakihara and Kishida [14] conducted laboratory tests on friction between cohesive soils and moderate steel using two types of apparatuses : a direct shear apparatus and a simple shear apparatus. Different types of soils were examined in this study, clay and sand-clay mixtures. They stated that there was little difference in the maximum friction coefficient between the tests with different mixture ratios of sand. Paikowsky et al., [15] indicated a series of laboratory tests using a modified direct shear apparatus and a modified simple shear apparatus. The test results showed that at a given applied vertical stress level, the major parameters which controlling the interface shear strength behaviour are particles shape and surface roughness. Recently, the influence of surface roughness on the shear strength behaviour of an interface between silty sand and a cement grout surface by means of direct shear apparatus is investigated by $\mathrm{Chu}$ and Yin [16]. Their results indicated that the soil-interface shearing resistance depends primarily on the surface roughness, water content of soil, and magnitude of the applied stress. The influence of soil water content, surface roughness and normal stress on the relationship between shear stress versus horizontal displacement was investigated by Shakir and Zhu [17] using simple shear apparatus. In their study, different concrete surface roughness's (smooth and rough) were used. Clay specimens were compacted at the same dry density with different water content ratios. They stated that the interface shear behaviour for both rough and smooth concrete surfaces governed by the interface sliding occurred within the interface layer between soil and concrete for all specimens except when the water content of specimen is greater than $16 \%$ for the case of rough concrete surface where the shear failure occurs within the soil body. Recently, Fleigh et al. [18] classified the interface friction behaviour into three failure modes, namely full sliding at the interface, shear failure within the soil and mixed behaviour where interface sliding and shear deformation of soil specimen proceed simultaneously. In their work, they performed a series of interface direct shear tests to study the effect of surface roughness and texture models on the friction angle between cohesive soils and steel.

\section{Research Objectives}

To the author's knowledge, there is inadequate literature available about the behaviour of interface shear strength of Iraqi soils. Hence, the aim of the present paper is to examine the influence of three major parameters namely surface roughness, soil water content and void ratio on the interface shear strength behaviour between silty sand soil and steel surface using direct shear apparatus.

\section{Laboratory testing}

\subsection{Material}

To achieve the goal of this research, synthetic soil specimens were prepared from sandy soil and kaolin since it could not be possible to find natural soil specimens from Iraq. The soil is prepared in the laboratory according to sieve analysis test results of soil obtained from AL-Rashedia site located in Nineveh governorate (495 km north of Baghdad) and published in a journal paper achieved by Khattab et al., [22]. Standard tests were carried out to determine the engineering properties of the prepared soil. Details are given in Table 1. According to the Unified Soil Classification System (USCS), the soil used in the investigation was classified as silty sand or SM. Fig. 1 shows particle-size distribution curves of the original and prepared soils, which indicate that the soil is composed of $73 \%$ sand, $19 \%$ silt, and $8 \%$ clay. Moreover, a standard compaction test was performed according to (ASTM D1577-02) by using a $2.5 \mathrm{~kg}$ rammer and a mould of $1000 \mathrm{~cm}^{3}$. Fig. 2 shows the relationship between the dry unit weight and water content of the soil used. The obtained maximum dry density is $20.20 \mathrm{kN} / \mathrm{m}^{3}$ with an optimum moisture content of $8.8 \%$.

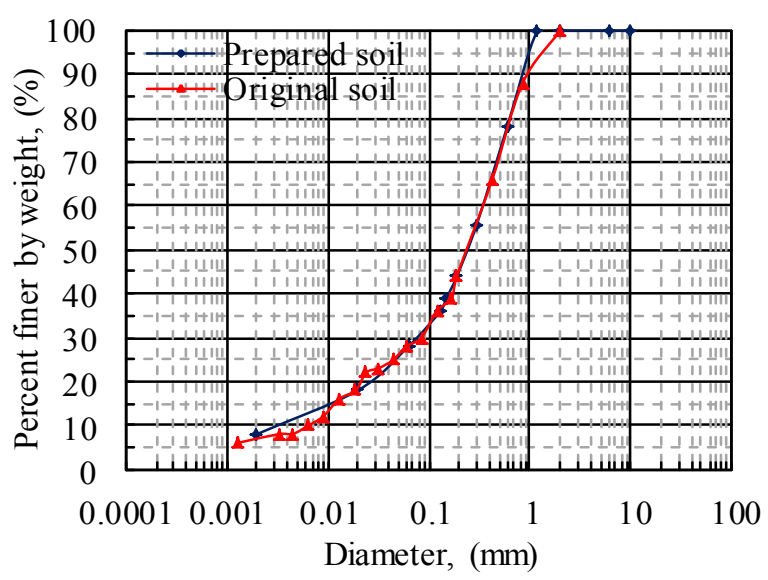

Fig. 1. Particle-size distribution curve of the soil

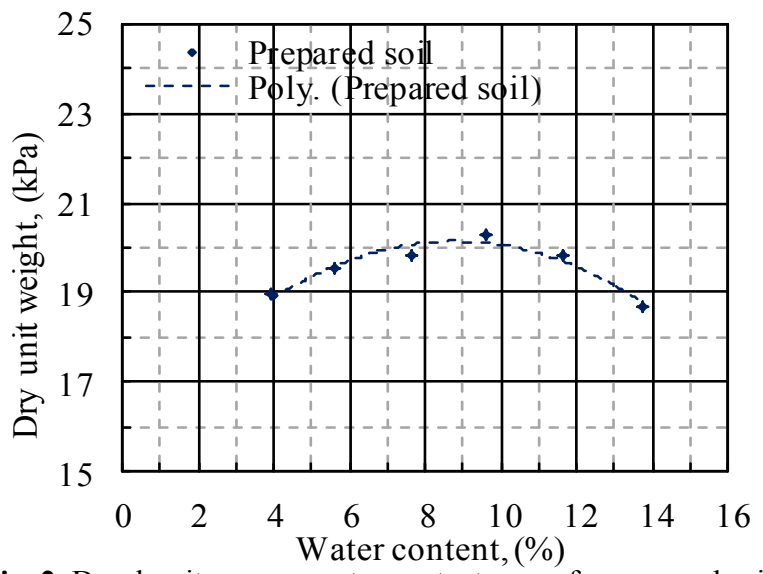

Fig. 2. Dry density versus water content curve for prepared soil

\subsection{Sample preperation}

In this research, the soil specimen used in the direct shear test was prepared in the laboratory and placed in the oven at a temperature of $105^{\circ} \mathrm{C}$ for 24 hours. Then, the desired quantity of soil was taken and appropriate amount of water was added to the target water content. 
The wet soil was wrapped in anti-evaporation plastic bags and stored in containers for 72 hours for water content equalization. For soil to soil specimen, the soil was compacted inside a square mould having inner dimensions of $60 \mathrm{~mm}$ by $60 \mathrm{~mm}$ and a height of $20 \mathrm{~mm}$. The soil was compacted in four layers of $5 \mathrm{~mm}$ thickness of each inside steel mould to the required density. The compaction was done by using a tamping rod. Finally, the mould with the specimen was placed over the upper half of shear box and the specimen pushed slowly inside the shear box until the specimen attached with the lower porous stone. The above procedure was adopted in preparing soil against steel direct shear specimen except that the wet soil was compacted in two layers of $5 \mathrm{~mm}$ each. Total number and types of tests performed for this study are presented in Table 2 .

Table 1. Index properties of prepared soil

\begin{tabular}{|l|c|c|}
\hline Soil property & Unit & Value \\
\hline Specific gravity (Gs) & ------- & 2.74 \\
\hline Liquid limit (L.L.) & $\%$ & 21 \\
\hline Plastic limit (P.L.) & $\%$ & 20 \\
\hline Plasticity index (P.I) & $\%$ & 1 \\
\hline Gravel & $\%$ & 0 \\
\hline Sand & $\%$ & 73 \\
\hline Silt & $\%$ & 19 \\
\hline Clay & $\%$ & 8 \\
\hline Standard maximum dry density & $\mathrm{kN} / \mathrm{m}^{3}$ & 20.20 \\
\hline Optimum water content & $\%$ & 8.8 \\
\hline $\mathrm{D}_{60}$ & $\mathrm{~mm}$ & 0.35 \\
\hline $\mathrm{D}_{50}$ & $\mathrm{~mm}$ & 0.25 \\
\hline $\mathrm{D}_{30}$ & $\mathrm{~mm}$ & 0.075 \\
\hline $\mathrm{D}_{10}$ & $\mathrm{~mm}$ & 0.004 \\
\hline Soil classification (USCS) & ------- & $\mathrm{SM}$ \\
\hline
\end{tabular}

Table 2. Total number and types of tests conducted for this study

\begin{tabular}{|c|c|c|c|c|c|}
\hline \multirow{2}{*}{ Parameter } & \multirow{2}{*}{ Interface } & \multicolumn{3}{|c|}{$\begin{array}{l}\text { Applied vertical } \\
\text { stress (kPa) }\end{array}$} & \multirow{2}{*}{$\begin{array}{c}\text { Test } \\
\text { condition }\end{array}$} \\
\hline & & 100 & 200 & 400 & \\
\hline \multirow{4}{*}{$\mathrm{e}=0.4$} & Soil & $\mathrm{x}$ & $\mathrm{x}$ & $\mathrm{x}$ & \multirow{4}{*}{$\begin{array}{l}\text { Consolidated } \\
\text { drained }\end{array}$} \\
\hline & Smooth & $\mathrm{x}$ & $\mathrm{x}$ & $\mathrm{x}$ & \\
\hline & Moderat & $x$ & $\mathrm{x}$ & $\mathrm{x}$ & \\
\hline & Rough & $\mathrm{x}$ & $\mathrm{x}$ & $\mathrm{x}$ & \\
\hline \multirow{4}{*}{$\mathrm{e}=0.6$} & Soil & $\mathrm{x}$ & $\mathrm{x}$ & $\mathrm{x}$ & \multirow{4}{*}{$\begin{array}{l}\text { Consolidated } \\
\text { drained }\end{array}$} \\
\hline & Smooth & $\mathrm{x}$ & $\mathrm{x}$ & $\mathrm{x}$ & \\
\hline & Moderat & $\mathrm{x}$ & $x$ & $\mathrm{x}$ & \\
\hline & Rough & $\mathrm{x}$ & $\mathrm{x}$ & $\mathrm{x}$ & \\
\hline \multirow{4}{*}{$\mathrm{e}=0.8$} & Soil & $\mathrm{x}$ & $\mathrm{x}$ & $\mathrm{x}$ & \multirow{4}{*}{$\begin{array}{l}\text { Consolidated } \\
\text { drained }\end{array}$} \\
\hline & Smooth & $\mathrm{x}$ & $\mathrm{x}$ & $\mathrm{x}$ & \\
\hline & Moderat & $\mathrm{x}$ & $\mathrm{x}$ & $\mathrm{x}$ & \\
\hline & Rough & $\mathrm{x}$ & $\mathrm{x}$ & $\mathrm{x}$ & \\
\hline \multirow{2}{*}{$\mathrm{e}=1$} & Soil & $\mathrm{x}$ & $x$ & $\mathrm{x}$ & \multirow{2}{*}{$\begin{array}{l}\text { Consolidated } \\
\text { drained }\end{array}$} \\
\hline & Smooth & $\mathrm{x}$ & $\mathrm{x}$ & $\mathrm{x}$ & \\
\hline
\end{tabular}

\begin{tabular}{|c|c|c|c|c|c|}
\hline & Moderat & $\mathrm{x}$ & $\mathrm{x}$ & $\mathrm{x}$ & \\
\hline & Rough & $x$ & $\mathrm{x}$ & $\mathrm{x}$ & \\
\hline \multirow{4}{*}{$\begin{array}{c}\omega= \\
4.5 \%\end{array}$} & Soil & $\mathrm{x}$ & $\mathrm{x}$ & $\mathrm{x}$ & \multirow{4}{*}{$\begin{array}{l}\text { Consolidated } \\
\text { drained }\end{array}$} \\
\hline & Smooth & $\mathrm{x}$ & $\mathrm{x}$ & $\mathrm{x}$ & \\
\hline & Moderat & $x$ & $\mathrm{x}$ & $\mathrm{x}$ & \\
\hline & Rough & $\mathrm{x}$ & $\mathrm{x}$ & $\mathrm{x}$ & \\
\hline \multirow{4}{*}{$\begin{array}{c}\omega= \\
8.8 \%\end{array}$} & Soil & $\mathrm{x}$ & $\mathrm{x}$ & $\mathrm{x}$ & \multirow{4}{*}{$\begin{array}{l}\text { Consolidated } \\
\text { drained }\end{array}$} \\
\hline & Smooth & $x$ & $\mathrm{x}$ & $\mathrm{x}$ & \\
\hline & Moderat & $x$ & $\mathrm{x}$ & $\mathrm{x}$ & \\
\hline & Rough & $\mathrm{x}$ & $\mathrm{x}$ & $\mathrm{x}$ & \\
\hline \multirow{4}{*}{$\begin{array}{c}\omega= \\
12.5 \%\end{array}$} & Soil & $\mathrm{x}$ & $\mathrm{x}$ & $\mathrm{x}$ & \multirow{4}{*}{$\begin{array}{l}\text { Consolidated } \\
\text { drained }\end{array}$} \\
\hline & Smooth & $\mathrm{x}$ & $\mathrm{x}$ & $\mathrm{x}$ & \\
\hline & Moderat & $\mathrm{x}$ & $\mathrm{x}$ & $\mathrm{x}$ & \\
\hline & Rough & $\mathrm{x}$ & $\mathrm{x}$ & $\mathrm{x}$ & \\
\hline
\end{tabular}

\subsection{Counterface}

In order to investigate the influence of surface roughness on the interface shear stress between soil and structures, three steel plates prepared from a steel sheet were used in this study as a counterface. All steel plates were manufactured having the same dimensions of $100 * 100 * 10 \mathrm{~mm}$, which is exactly the same as the size of lower half of shear box. Three different surfaces roughness (smooth, semi-rough, and rough) were performed as shown in Fig. 3. The completely smooth surface polished by fine sandpaper [2]. A value of $0.0025 \mathrm{~mm}$ was used as a peak to valley height for smooth steel plate [25]. Uesugi and Kishida [3] defined the normalized surface roughness, $R_{n}$ as a maximum peak to valley height, $R_{\max }$ divided by grain size dimeter corresponding to $50 \%$ finer, $\mathrm{D}_{50}$. Based on the particlesize analysis curve, the normalized surface roughness of smooth, moderate and rough steel plates were equal to $0.01,4$, and 8 respectively.

(a)

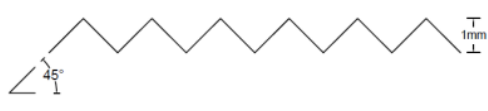

(b)

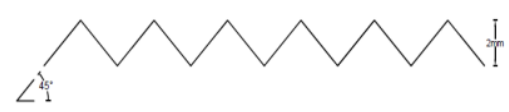

Fig. 3. Surface geometry of (a) semi-rough: and (b) rough

\section{Soil testing method}

A fully automated commercially direct shear apparatus was used in this study. All tests were performed according to (ASTM D3080-04). The test procedure consists of three stages :- saturation, consolidation and shearing stages. After placing the soil specimen inside the shear box, the specimen was soaked in water for 24 hours to ensure that the voids are completely filled with water. After saturation, the specimen was consolidated under three applied vertical stresses of 100, 200 and 400 $\mathrm{kPa}$. The consolidation process continues until the 
vertical deformation versus horizontal displacement curve is levelled off. After consolidation attained, a shearing stage was performed under drained condition with a constant horizontal shearing rate of $0.06 \mathrm{~mm} / \mathrm{min}$ for all specimens (i.e. soil versus soil and soil versus interface).

\section{Test results and analysis}

\subsection{Test results of soil to soil specimens}

Single stage direct shear tests were performed on initially saturated soil to soil specimens under different applied vertical stresses of 100,200 and $400 \mathrm{kPa}$. The effect of different water content and void ratio on the shear strength behaviour of compacted silty sand soil are presented and discussed in the following sections.

\subsubsection{Influence of water content on shear strength behaviour}

Typical direct shear test results are presented in terms of shear stress versus horizontal shear stress displacement curves for soil specimens tested at different water contents $(4.5 \%, 8.8 \%$ and $12.5 \%)$ under 100,200 and $400 \mathrm{kPa}$ applied vertical stress respectively are shown in Fig. 4a-c. Soil specimens of dry and wet side of optimum were compacted at same dry density $\left(19.2 \mathrm{kN} / \mathrm{m}^{3}\right)$ with different water content (4.5\% and $12.5 \%)$. As expected, all specimens exhibited a hardening behaviour at beginning of shearing stage until peak shear stress followed by different patterns of shear behaviours (softening and/or hardening). These figures also illustrated that the shear strength increased with the increasing of applied vertical stress. Regardless of the value of vertical stress, specimens compacted at dry side of optimum exhibited higher shear stress compared with those tested at wet side of optimum. These findings coincide with the findings reported by Tiwari and AlAdhadh, [11]. Fig. 4 also indicates that clear peak shear stress and softening behaviour are obvious for specimens carried out under $400 \mathrm{kPa}$ vertical stress. Fig. 5 depicts Mohr-Coulomb shear envelopes obtained from the three different types of tests. As expected, specimens compacted at optimum water content had higher shear strength compared to those tested at dry and wet side of optimum for all vertical stresses. However, dry side of optimum specimens showed higher shear strength than those compacted at wet side of optimum. Vanapalli et al., [19] and Cokca et al., [20] found the same results. The shear strength parameters along with the water content are summarized in Table 3. As can be seen in Table 3, a significant reduction was observed in the effective cohesion with an increase in water content. In addition, effective friction angle decreased as water content decreased. For example, friction angle decreased from $30^{\circ}$ to $29^{\circ}$ when water content increased from $4.5 \%$ at dry side to $12.5 \%$ at wet side of optimum.
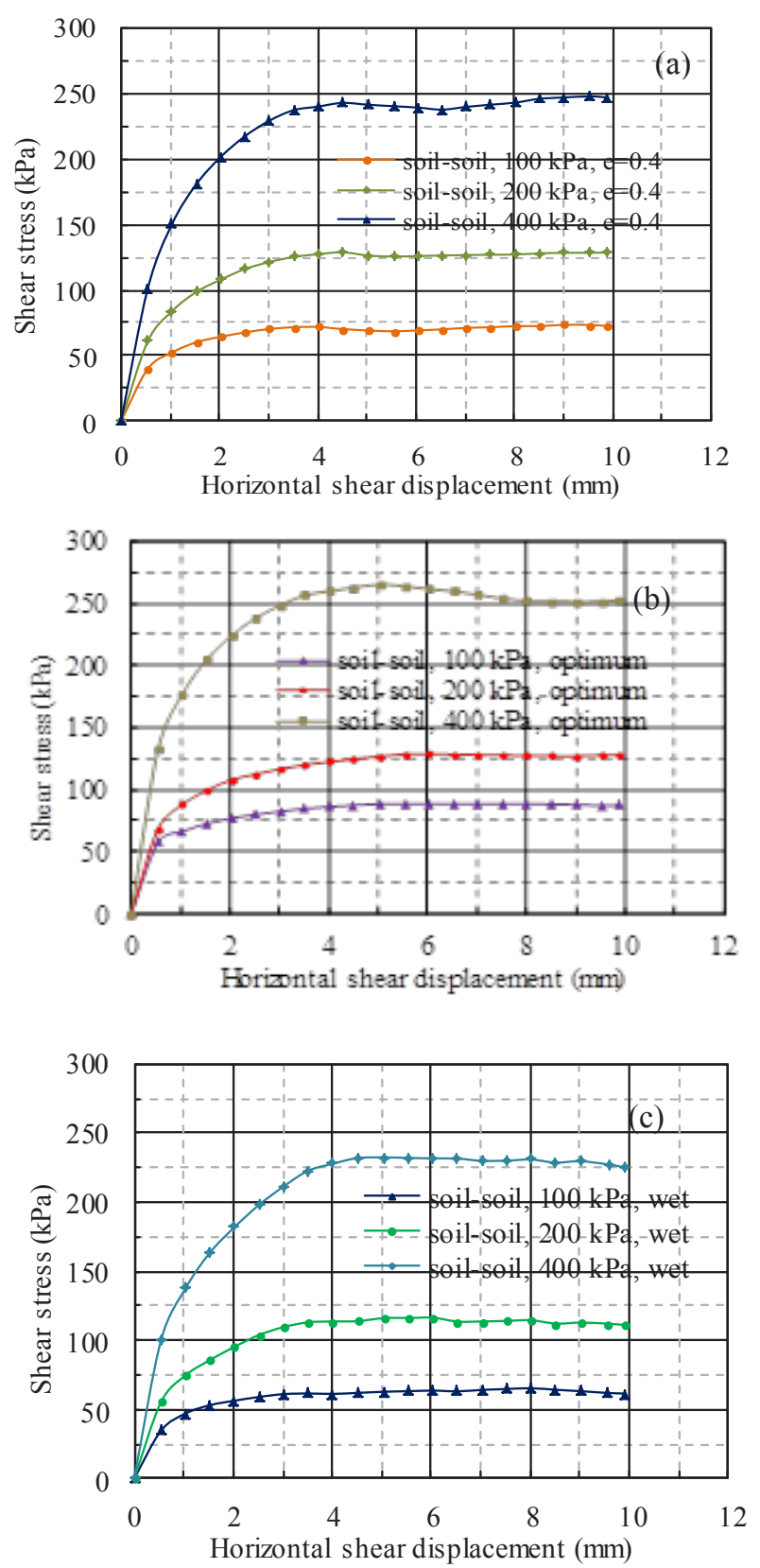

Fig. 4. Direct shear test results for soil to soil specimens compacted at different water content (a) dry; (b) optimum; and (c) wet

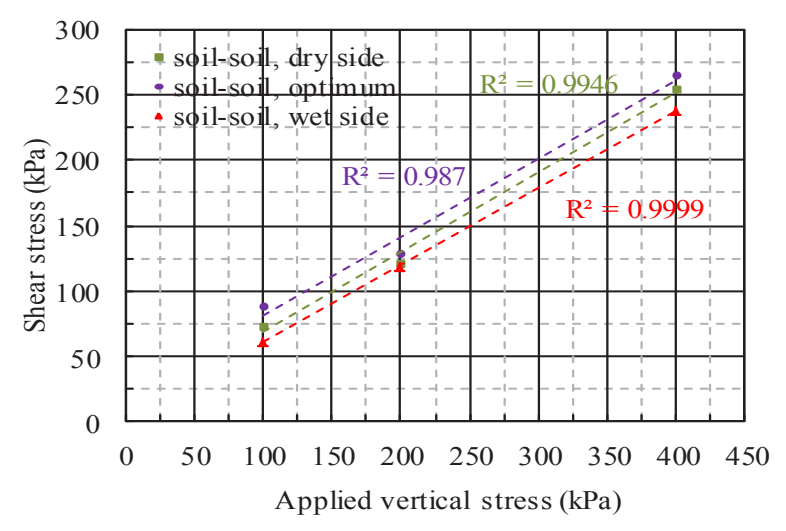

Fig. 5. Failure envelopes corresponding to different water content 
Table 3. Shear strength parameters from different water content tests

\begin{tabular}{|l|c|c|}
\hline Water content (\%) & $\boldsymbol{\Phi}^{\prime}(\mathbf{d e g})$ & $\mathbf{c}^{\prime} \mathbf{( k P a )}$ \\
\hline Dry side $=4.5$ & 30 & 10 \\
\hline Optimum $=8.8$ & 31.5 & 21 \\
\hline Wet side $=12.5$ & 29 & 4 \\
\hline
\end{tabular}

\subsubsection{Influence of void ratio on shear strength behaviour}

Twelve consolidated drained direct shear tests were carried out on the saturated silty sand under three vertical stresses and four different void ratios. Fig. 6a-d shows shear stress versus horizontal displacement curves for soil specimens performed at different void ratios $(0.4$, $0.6,0.8$, and 1) and water content equal to $7 \%$. It can be seen from Figure 6 that the shear stress decreased with increasing of void ratio for all applied vertical stresses. As can be observed, the maximum shear stress increases as the vertical stress increases for all void ratios. It can be also noticed that the dense specimens (low void ratio) exhibited peak shear stress more clearly than the loose specimens (high void ratio). The values of maximum shear stress from all tests are plotted against applied vertical stress in Fig. 7. The shear strength envelopes for various void ratios are approximately linear. Moreover, the shear strength parameters $\phi^{\prime}$ and $c^{\prime}$ decrease with an increasing of void ratio as shown in Table 4 . The experimental shear strength result agrees with the findings reported by Tiwari and Al-Adhadh [11].
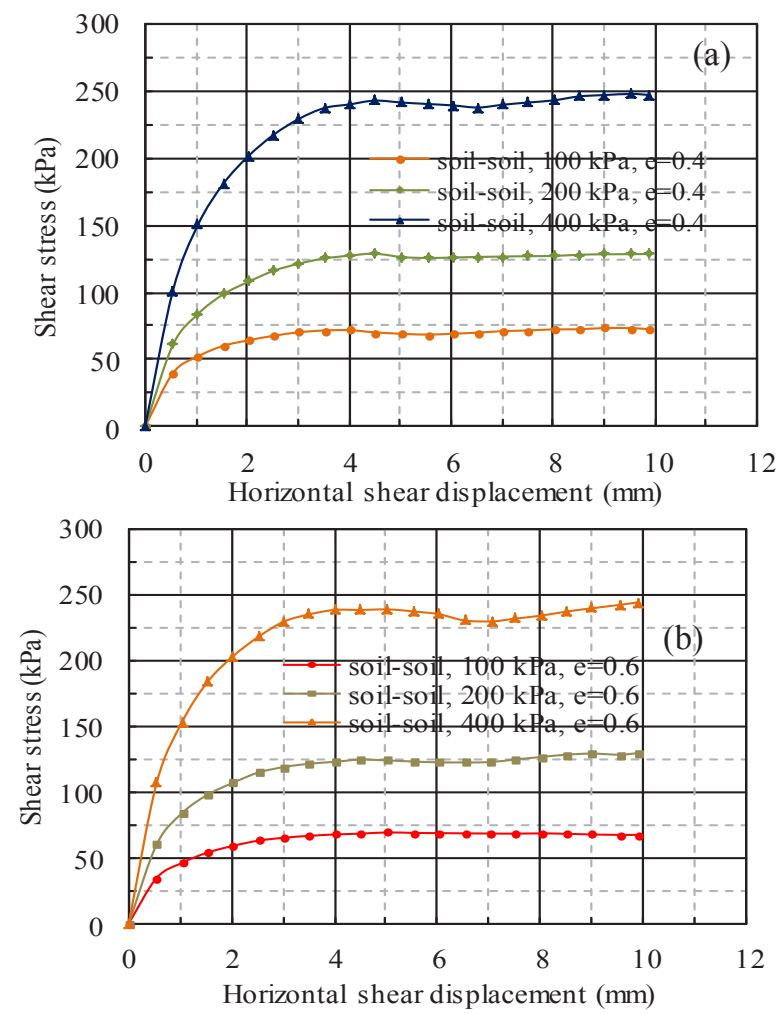
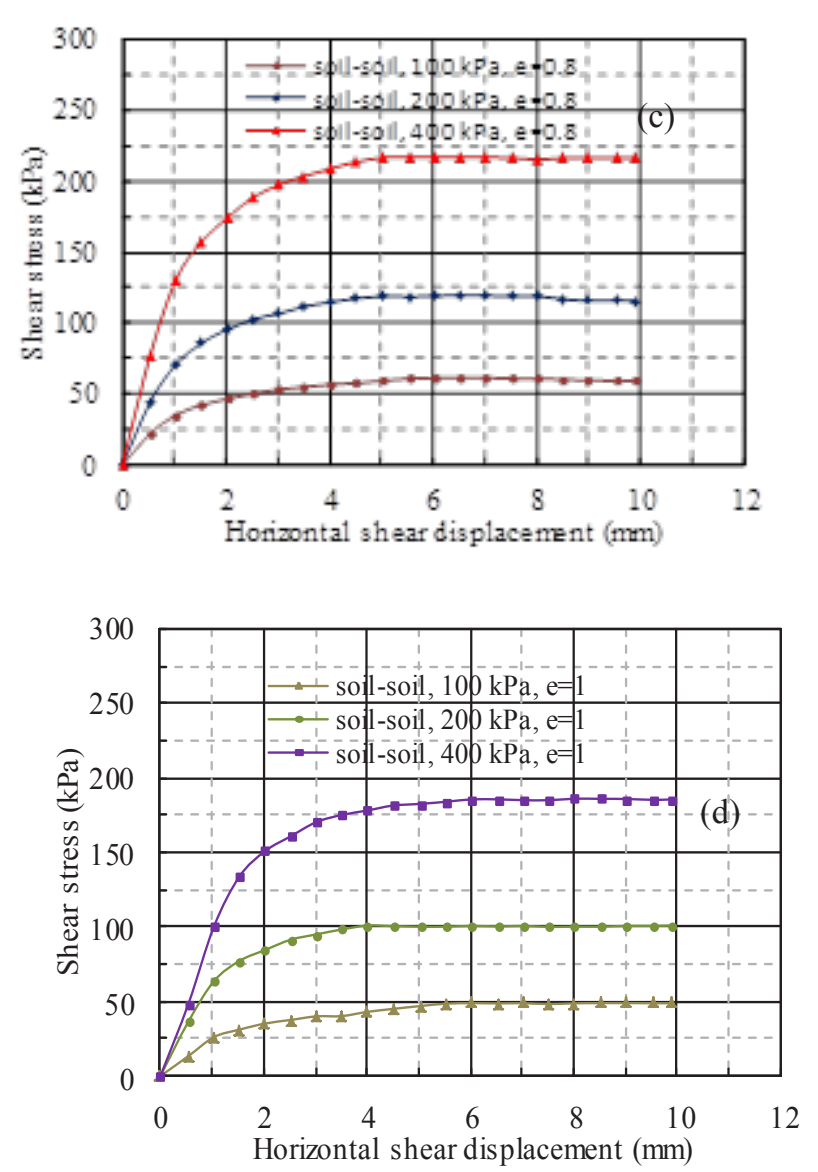

Fig. 6. Direct shear test results for soil to soil specimens compacted at different void ratios (a) 0.4 ; (b) 0.6 ; (c) 0.8 ; and (d) 1

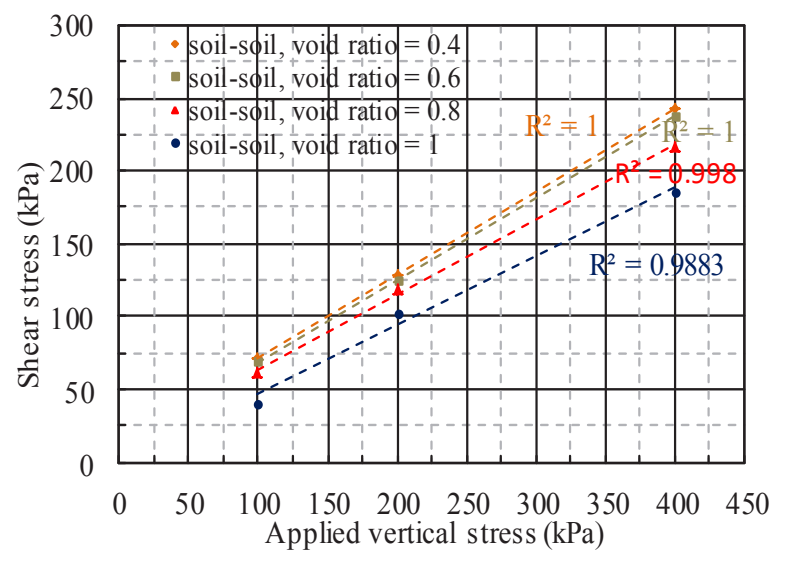

Fig. 7. Failure envelopes corresponding to different void ratios

Table 4. Shear strength parameters from different void ratio tests

\begin{tabular}{|c|c|c|}
\hline Void ratio & $\boldsymbol{\phi}^{\prime}(\mathbf{d e g})$ & $\mathbf{c}^{\prime} \mathbf{( k P a )}$ \\
\hline 0.4 & 29 & 20 \\
\hline 0.6 & 28.5 & 19 \\
\hline 0.8 & 26.5 & 15 \\
\hline 1 & 24 & 0 \\
\hline
\end{tabular}

\subsection{Interface shear tests}


This study is set out with the aim of assessing the importance of surface roughness on the shear strength of soil. To do this, a series of interface direct shear tests were carried out to examine the effect of three types of steel surface roughness on the interface shear strength at different void ratios and water content. Curves of shear stress versus horizontal shear displacement for different water content ( $4.5 \%$ and $12.5 \%)$ sheared against smooth, semi-rough, and rough steel surfaces under applied vertical stress of $400 \mathrm{kPa}$ are plotted in Fig. 8a-b. Similar behaviour was observed while the specimens were examined under other vertical stresses. It is interesting to note that the shear stress increased with an increase in the surface roughness increases for both dry and wet side of optimum conditions. As can observed from Figure 8ab that the interface shear strength of specimen with rough steel significantly increased approximately by 1.5 folds and 2 folds for specimens with $4.5 \%$ and $12.5 \%$ water content, respectively It can be also observed that the curves for rough surface exhibited peak shear stress followed by softening behaviour. As opposed to the rough interface, curves of smooth interface showing no peak shear stress followed by steady state condition. The failure envelopes for soil-steel interfaces performed under different water content are shown in Fig. 9a-b. The failure envelopes are found to be linear. It can be also noticed that there was a remarkable reduction in the interface shear strength compared to the shear strength of soil. The highest reduction was observed for soil sheared against smooth interface compared to the specimens sheared against semi-rough and rough interfaces. This trend was observed for all water content values.
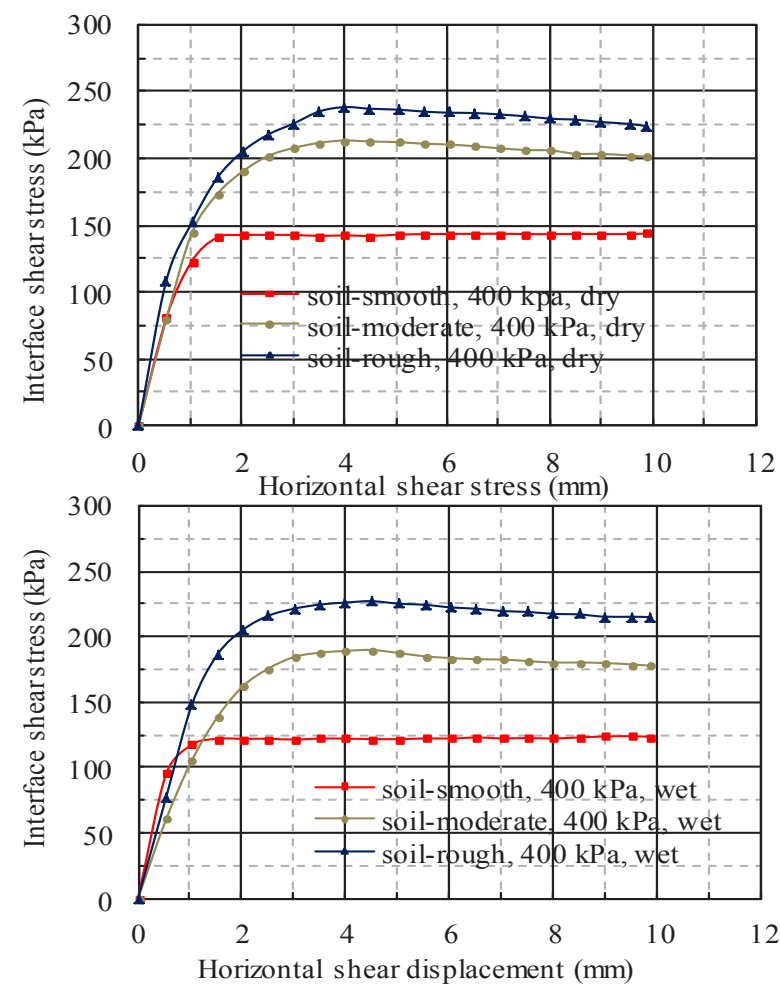

Fig. 8 Direct shear test results for soil to interface specimens compacted at different water content (a) dry; (b) wet
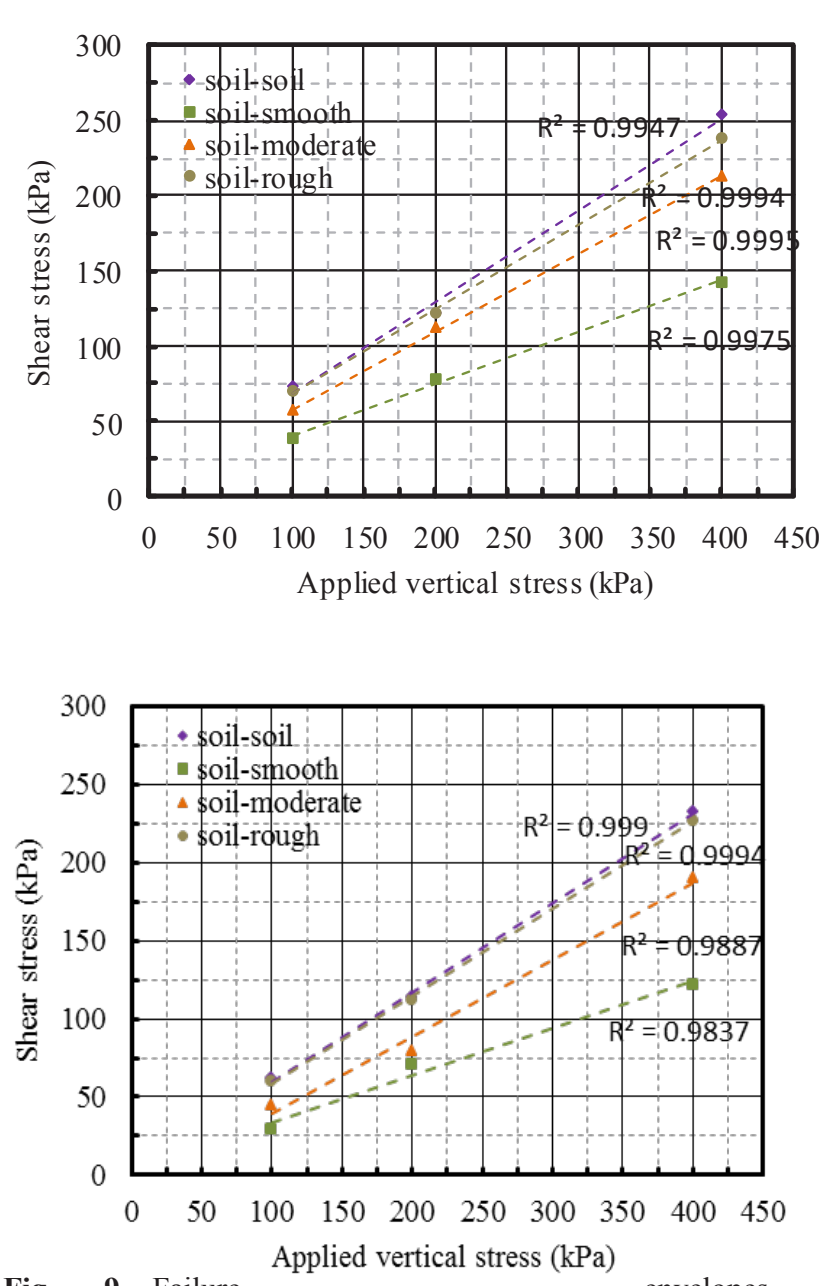

Fig. 9. Failure

envelopes

for the soil to soil and soil to interface for specimens compacted at different water content (a) dry; and (b) wet

These results are consistent with those reported by [21]. The shear strength parameters along with the water content are summarized in Table 5.

Table 5. Shear strength parameters from different water content tests

\begin{tabular}{|c|c|c|c|}
\hline Interface & $\begin{array}{c}\text { Water } \\
\text { content }(\%)\end{array}$ & $\phi^{\prime}(\operatorname{deg})$ & $\mathrm{c}^{\prime}(\mathrm{kPa})$ \\
\hline Soil & \multirow{4}{*}{4.5} & 30.5 & 10 \\
\hline Smooth & & 18.5 & 6 \\
\hline Semi-smooth & & 26.5 & 7.5 \\
\hline Rough & & 28.5 & 12 \\
\hline Soil & \multirow{4}{*}{12.5} & 29 & 6 \\
\hline Smooth & & 15.5 & 4 \\
\hline Semi-smooth & & 25 & 0 \\
\hline Rough & & 27 & 5 \\
\hline
\end{tabular}

Likewise, the results of interface direct shear tests for the soil specimens with 0.4 and 1 void ratio are presented in Figure 10a-b tested under applied vertical stress of 400 $\mathrm{kPa}$. Similar behaviour was observed while the specimens were carried out under other applied vertical stresses. As evident, there is a consistent increase in the 
interface shear stress with an increase in the surface roughness irrespective of whether the void ratio was 0.4 or 1. As could observed from Fig. 10a-b that the interface shear strength of specimen with rough steel significantly increased approximately by 3 folds and 1.6 folds for specimens with 0.4 and 1 void ratios respectively. It can be also noticed that the curves for rough surface exhibited peak shear stress followed by softening behaviour. As opposed to the rough interface, curves of smooth interface showing no peak shear stress followed by steady state condition. In general, it is observable that the void ratio has a remarkable influence on the interface shear stress. For example, the maximum shear stress for rough interface decreased by $28 \%$ when the void ratio increased from 0.4 to 1 . The presented findings seem to be consistent with the results observed by previous researchers such as $[2,12,10,21]$. The values of peak shear stress form all tests are plotted against the vertical stress in Fig. 11a-b, for different void ratios. The interface failure envelopes for various interfaces roughness are approximately linear. Similar to interface direct shear results under different water content, a significant reduction in the interface shearing resistance compared to the shearing resistance of soil. The highest reduction was observed for soil sheared against smooth interface compared to the specimens sheared against semi-rough and rough interfaces. The shear strength parameters along with the void ratios are tabulated in Table 6. In addition, Figure 12a-b illustrates the influence of surface roughness on the interface angle of friction.
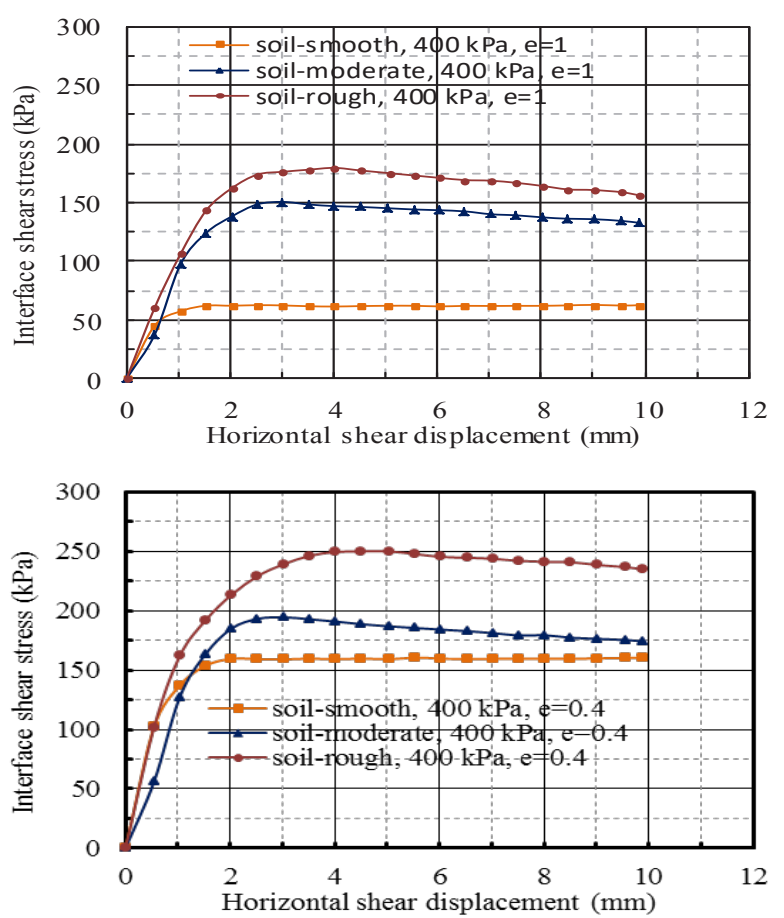

Fig. 10. Direct shear tests results for soil to interface specimens compacted at different void ratios (a) 0.4; (b) 1
Table 6. Shear strength parameters of soil and interfaces

\begin{tabular}{|c|c|c|c|}
\hline Interface & Void ratio & $\Phi^{\prime}(\operatorname{deg})$ & $c^{\prime}(\mathrm{kPa})$ \\
\hline Soil & \multirow{4}{*}{0.4} & 30.5 & 17 \\
\hline Smooth & & 20 & 8 \\
\hline $\begin{array}{l}\text { Semi- } \\
\text { rough }\end{array}$ & & 24 & 13 \\
\hline Rough & & 30 & 16 \\
\hline Soil & \multirow{4}{*}{1} & 24 & 7 \\
\hline Smooth & & 5.5 & 23 \\
\hline $\begin{array}{l}\text { Semi- } \\
\text { rough }\end{array}$ & & 19 & 0 \\
\hline Rough & & 22.5 & 5 \\
\hline
\end{tabular}
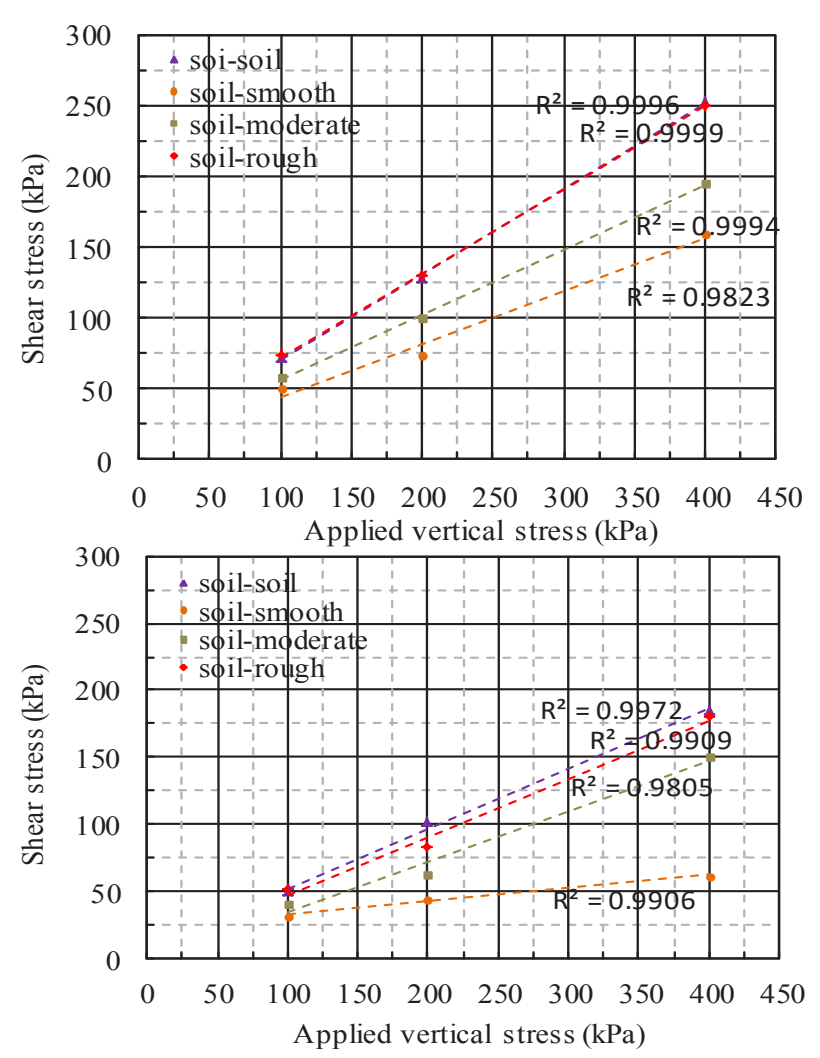

Fig. 11. Failure envelopes for the soil to soil and soil to interface for specimens compacted at different void ratios (a) 0.4 ; and (b) 1

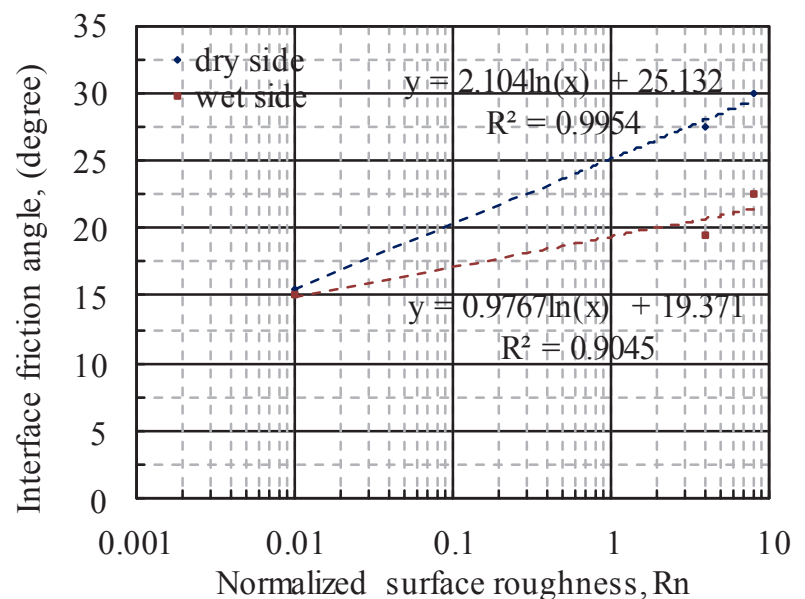




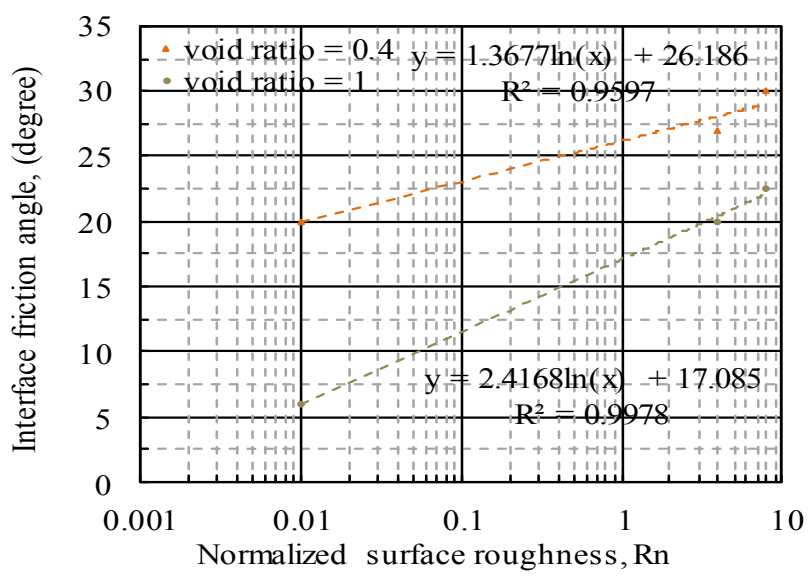

Fig. 12. Influence of surface roughness on the interface friction angle

\section{Conclusions}

Consolidated drained direct shear tests were carried out to investigate the influence of water content, void ratio, and surface roughness on the interface shear strength between silty sand and steel plate. Three types of surface roughness (smooth, semi-rough, and rough) were used. The specimens were compacted at different water contents $(4.5 \%, 8.8 \%$, and $12.5 \%)$ and void ratio $(0.4,0.6,0.8$, and 1$)$. Based on the results obtained the following conclusions are summarized.

1. The shear strength of soil increases with decreasing both water content and void ratio.

2. Soil shear strength increased with increasing of applied vertical stress. Based on the presented results, it can be seen that soil shear strength was higher than the interface shear strength of smooth, semi-rough and rough interfaces.

3. The interface shear stress increases with increasing the surface roughness. Therefore, from the geotechnical point of view, rough steel surface can be used to increase the interface shear strength of some geotechnical structures such as steel pile foundation and offshore structures.

4. The interface friction angle of different surface roughness increases as the surface roughness increases. Interface friction angle increased by $50 \%$ when the surface roughness changed from the smooth to the rough surface for specimens compacted at dry side of optimum.

5. Based on the results, void ratio and water content had an obvious influence on the interface friction angle between soil and steel plates. Referring to the results, high water content and low void ratio produced small friction angle.

\section{References}

1. Y. B. Acar, H.T. Durgunoglu, M. T Tumay, J. of Geo. Eng. ASCE, 108, GT4, (1982).

2. J. G. Potyondy, Geotechnique, 11, (1961).
3. M. Uesugi, and H. Kishida, Soils and Found.,26, 4, (1986).

4. Y. Yoshimi, and T. Kishida, 10th Int. Conf. on Soil Mech. and Found. Eng., 1, (1981),

5. K. Fakharian, and E. Evgin, Geo. Tes. J., 19, 1, (1996).

6. J. L. Briaud, T. D. Smith, and B. Meyer, Symp. on the Press. and Its Marine App., Paris. (1982).

7. T. R. Smith, and B. Ray, Geo. Asp. of Stiff and Hard Clays, Ed. Khera and Lovell, ASCE, New York, (1986).

8. C. S. Desai, E. C. Drumm, and M. M. Zaman, ASCE, J. of Geo. Eng., 111, 6, (1985).

9. W. F. Brumund, and G. A. Leonards, J. of Test. and Eva., JTEVA, 1, 2, (1973).

10. A. I. Al-Mhaidib, Eng. J. of the Uni. of Qatar, 19, 2, (2006).

11. B. Tiwari, and A. Al-Adhadh, Geo. Geol Eng, 32, (2014).

12. F. H. Kulhawy and M. S. Peterson, $6^{\text {th }}$ PanAmerican Conf. on Soil Mech. and Found. Eng., 7, (1979).

13. Y. Tsubakihara, and H. Kishida, Soils and Found. 33, 2, (1993).

14. S. G. Paikowsky, C. M. Player, and P. J. Connors, Geo. Test. J., 18, 2, (1995).

15. L. M. Chu, and J. H. Yin, Geomech. and Geoeng., 1, 4, (2006).

16. R. R. Shakir, and J. Zhu, J. Fron. of Arch. and Civ. Eng. in China, 3, (2009).

17. M. Feligha, F. Hammoud, M. Belachia, and M. S. Nouaoria, Geotech Geol Eng, 34, (2016).

18. E. Cokca, O. Erol, and F. Armangil, Geot. and Geo. Eng., 22, (2004).

19. S.K. Vanapalli, D.G. Fredlund, D.E. Pufahl, and A.W. Clifton, Can. Geot. J., 33, (1996).

20. S.E. Mousavi, Transactions B: Applications, 29, 2, (2016).

21. S.A. Khattab, E. M. Mohammad, and M. G. Jassam, Tik. J. of Eng. Sci., 19, 3, (2012).

22. T. Hamid, Ph.D. dissert. School of Civ. Eng. and Envi. Sci., Univ. of Oklah., Norman, Okla., (2005). 